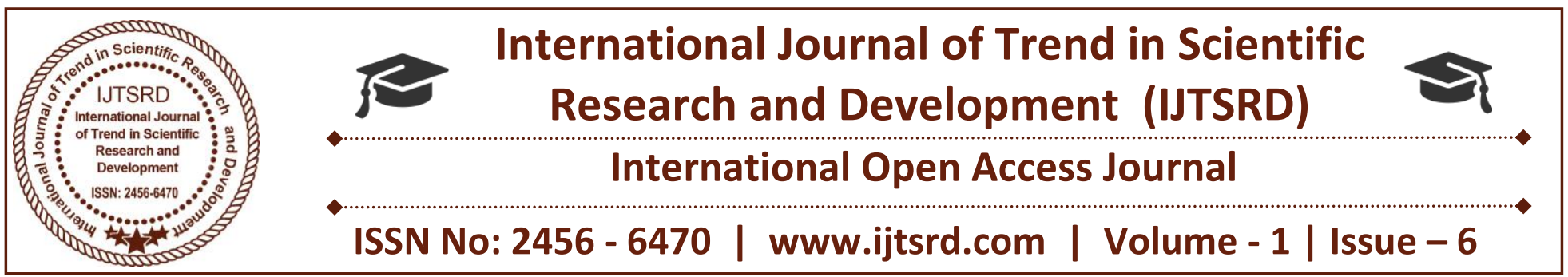

\title{
Remedial Measures to Improve the Living Conditions of Slump Dwellers as a Step in the Journey towards a Smart City : An Overview
}

\author{
S.S. Sisodia \\ Asst. Professor, Civil Engg. Department \\ Maharishi Arvind International Institute Of \\ Technology, Kota, Rajasthan
}

\author{
Kamal kant \\ Lecturer, Civil Engg. Department \\ Maharishi Arvind International Institute Of \\ Technology, Kota, Rajasthan
}

\begin{abstract}
Cities are the response to social, political or technological transformations. They reflect our aspirations and respond to the challenges of the era. We are becoming a nation of 'cities and towns'. In India the population ratio between the rural and urban is changing fast. Present scenario of the villages is that land holding farmers have divided in small land they became small farmer and marginal farmers so one family cannot be survive on this land hence resident run to cites for their earning and better live hood. Today $17 \%$ of our population is of slum dwellers. Agriculture has become more efficient as also its machinery, and needs far fewer people. Unemployment and even underemployment have become a worrisome phenomenon in Indian villages the attraction of cities with its thousand lights has become irresistible.
\end{abstract}

Can our cities absorb this exodus? In India the whole exodus has been accommodated in the existing structures. This has led to the creation of slums in India. Even basic needs such as accommodation, energy, water, and sanitation are in short supply. Are these deprivations remediable?? Can we clean up our cities or build new ones? If we go in for building new cities, can we integrate such initiatives with the answers that new technologies provide??

Slums are an unhappy reality for our country and many others across the world. In India the total number of slum dwellers are about 65 million! Slums are a major urban drawback and a huge hurdle in the country's development at the same time people living there are a part of our working system!! We need to think whether the broad term SMART CITIES is good enough for India or we could have smart cities, smart slums and smart rural sector because the financial hurdles will always keep them on different racks of the ladder. We believe that Smart cities should focus on developing smart techniques of social awareness for the slum dwellers so that they can consciously work for a better living rather than be happy in the dump.

India, the second most populated country on the planet, is projected to add another 404 million urban dwellers by 2050, the largest addition in the world, followed by China with 292 million, a UN report this year said.

Delhi, already the world's second largest city after Tokyo, where many live in slums or on streets and building sites where they labour, is expected to rise swiftly to 36 million by 2030 . In India the total number of slum dweller totals about 65 million, of which Maharashtra alone accounts for 11 million. Next come Andhra Pradesh, with a slum population of 10 million, followed by West Bengal and Uttar Pradesh, with over 6 million each. The figures are 
indeed staggering. Slums are a major urban drawback and a huge hurdle in the country's development

Modiji's pledge to build 100 "smart" cities as part of an ambitious agenda of reform and economic development has millions flocking from the countryside in search of jobs and stretching some cities to near breaking point and pushing the poor further into the outskirts

The predicted new cities would give rise to exclusive so-called gated communities, while the poor remained squeezed into ever-growing and sometimes illegally built slums with few services.

"There are a large number of people who want to move out of poverty, to move out of the slums, but they don't know how. We are not focusing on that. There is a strong need for awareness programmes for slum dwellers telling them how they can make their lives better, how shifting to a low cost housing would not mean loss of work, make them aware of better transportation network, how to use facilities government provides for them, as most of them are illiterate and don't even know that there are certain benefit programmes which are there for their betterment.

Slum dweller kumar in delhi states that he has seen the city grow over the past 17 years he has been staying in the slum where he has seen flyovers and a metro develop. He feels their state in the slum has deteriorated and population has grown. His two room shack along with hundreds of others was suddenly demolished recently for encroaching on state forest land. Is demolition of slums a solution??

Smart cities should have a chalked out agenda for educating the slum dwellers, understanding the fears that they face and working on them. A govt committee should be formed who can actually do a survey to find out why even after relocating them the slum dwellers come back to the streets. We finally need to cross their mental barriers to be able to physically relocate them successfully.

Personally having spoken to a few dwellers staying under the over bridge under extremely unhygienic conditions do not want to go and stay in any govt shelter as they feel they will be restricted from a lot their daily activities and they love it here.

A complete analysis of what kind of work they do listing each and every little one, what are their activities morning to evening, their source of entertainment, what they do for their sanitation and finally how many are literate and the ratio of children not going to school.

Till the time each activity is not understood and a provision made for everything that they would actually need for their livelihood

\section{Identify Problems in Slums Areas}

Within a slum problems are manifold: living conditions are deplorable, crime rate is high, sanitation is poor, child mortality is high, education levels are low and diseases are rampant. But the situation has to be tackled and the issues have to be faced.

\section{CONCLUSION}

Provision of tenancy rights to slum dwellers in order to ensure that their housing is not infringed upon by government agencies. Slum dwellers often fear rehabilitation because it affects their access to means of livelihood. The idea behind ensuring tenure is that once they lose their fear of being evicted, the slum dwellers can work to improve their quality of life. In due course they can purchase the land they currently inhabit.

Building low-cost residences for slum dwellers so that proper housing can ensure their safety and hygiene

$>$ Making clean water available

$>$ Encouraging proper sanitation and waste management

$>$ Controlling pollution levels

$>$ Providing transport facilities

$>$ Arranging for informal education

$>$ Making credit and finance available as per requirement

$>$ Introducing new programmes for incomegeneration

$>$ Providing a platform for sharing ideas, inputs and experiences

Facilities for Small industries should be providing so that self employment may be generated at town level. Similarly improvement agriculture technique is given to improve the production of the agriculture latest high breed seeds should be provide as well as required weedicide, pesticides. So that production of agriculture could not be hampered. 
However, these are only broad guidelines and there can be no single uniform model for urban planning which can be used globally. Slum rehabilitation and upgrading are vital, but each city has certain distinctive political, cultural, environmental and economic factors which determine the extent to which such rehabilitation is feasible. Hence, proper assessment has to be made and prospects evaluated before the problem can be addressed. Slum dwellers need to made aware of the need for improvement in living conditions, and they must readily involve themselves with every phase of the rehabilitation. Practical and innovative approaches need to be put into practice to integrate slums within the cities. Governments need to pay more attention to slums and make concerted attempts to address this problem proactively. One-seventh of the world's population is in slums right now. It is indeed time for urgent action. Why can we not hear the alarm bell ring?

\section{REFERENCES}

1) https://www.ritimo.org/Slum-Settlements-on-

Railway-Land-A-State-of-Denial-and-Deprivation

2) Census Data 2011 (Government of India)

Human Development Report on Bombay Municipal Corporation by the United Nations Development Programme

RTIs filed to RLDA and the Ministry of Railways, India.

3) Government of India

Ministry of Urban Development (June, 2015)

4) NAGAR NIGAM KOTA (RAJASTHAN)

5) http://timesofindia.indiatimes.com/india 